\title{
Problems Might Be Encountered in the Implementation of General Practitioner Training Mode and the Optimizing Strategies
}

\author{
Qiang Wang \\ Xi'an Peihua University, Xi'an, 710125, China
}

Keywords: General practitioner, Training mode, Significance, Problems, Countermeasures

\begin{abstract}
With the progress and development of society, comprehensive talents become the main competitive object of present society. Strengthening the training of general practitioner is very important for hospitals to improve their medical level to meet social demands. Therefore, this paper mainly analyze the problems encountered in the process of nurturing general practitioners and the countermeasures.
\end{abstract}

\section{Introduction}

In recent years, with the development of medical health system, developing a medical service team with high quality and high level becomes the important task of hospital development, government also issued a series of rules and regulations to promote the talents training. But because of the influence of system and social factors,the general practitioner training also has some problems,thus need to arouse attention of related personnel, find out the reasons, improve this situation through taking relevant measures, thus to strengthen general practitioner training to promote the development of medical institutions.

\section{Problems encountered in the implementation of general practitioner training mode}

\section{Quality and quantity of general practitioners}

Quantity of general practitioners is small

At present,the quantity of general practitioner in our country is very limited, especially the economically undeveloped areas are more obvious. For example, there are no general practitioners with bachelor degree work for the health agencies in many undeveloped areas in Guangxi province for many years, their medical level is pretty low. This is mainly because there is lack of understanding for general practitioners in our country, together with the influence of general practitioners' working objects and working features, most of students will not consider relevant majors, thus leads to the small quantity of general practitioners.

General practitioners are with low education background

There is a phenomenon that many general practitioners are with low education background and low job title, many rural doctors cannot reach the qualification of doctor examination. According to the survey, doctors with college degree or above in the many township hospitals are less than a quarter, while doctors with technical secondary degree or below become the main force for the development of hospitals. Until 2013, doctors with bachelors degree reached around one third, above college reached three-fifths, there is a huge space with the requirements of the developed countries ${ }^{[1]}$.

The general practitioner team is not stable

Because of the relative bad work environment and social benefits, many doctors do not want to engage in this industry, there are some doctors treat it as a stepping stone, once they meet a better opportunity, they will change immediately, thus made the general practitioners team become very unstable, and also hard to attract excellent talents, thus made the low level of the medical team and cannot meet people's demands, and influenced the development of the medical level of the grassroots. 


\section{Problems in the general practitioner training}

The discipline construction of general practitioner is very slow

Currently, many colleges in our country are lack of comprehensive and profound understanding on general practitioners, their discipline constructions are very slow, when they apply the national or provincial research projects, they cannot classify the general practitioner in the research range. Not only that, many colleges in our country have no general practitioner major at present, they are lack of necessary attention for general practitioner, this forms a striking contrast with the developed countries. According to related survey, in 1020, among the 128 colleges with medical majors, only half of them set the major of general practitioner, while only 12 colleges among them have practical activities, and the time for every class is relative long, this is not benefit for the construction of general practitioner training mode, thus needs to improve college's cognition for the importance of general practitioner, speed up the construction of general practitioner major, and train more excellent talents ${ }^{[2]}$ for society.

Teaching levels of general practitioner need to be improved

The education department once issued related regulations and measures to further promote the construction of general practice, and had listed the contents such as writing textbooks and strengthening teachers teams in it. But many colleges in our country had not practiced relevant contents during the process of implementation, thus lead the training of general practitioners are not satisfied. The key factor is lacking of high quality teaching teams, main expressed in: firstly, teachers for general practitioners are mainly part-time teachers. Secondly, lack training for teachers. Thirdly, lack of practice base.

Lack of colleges directional recruit general practitioners

Currently, colleges in our country have seldom recruit undergraduates and college students, most of recruit for national policy, to provide talents for rural medical system. But because these colleges are with weak teaching, undeveloped teaching concept, low teaching levels, thus their study effect is not very satisfactory ${ }^{[3]}$.

\section{Main measures for solving general practitioner training mode}

\section{Pay more attention to general practitioner training}

General practitioner training first needs to arouse attention of relevant personnel and departments, thus to gain necessary supports. Therefore, general practitioner training should be implied from following aspects: firstly, strengthen governmental attention. Governments can promote general practitioner training policy and encourage hospitals to strengthen general practitioner training; secondly, strengthen hospitals' attention. Hospitals also need to change managing concept, strengthen genera practitioner training sense to improve the quality and efficient of medical working; thirdly, strengthen the implementation of relevant policy. Strengthening the attention for genera practitioner training can stimulate colleges or hospitals implement relevant policy, strengthen the assessment for doctors' performance through establish a new subject and improve genera practitioner training $^{[4]}$. At the same time, arouse the attention of doctors and students who will be doctors, make they become be to genera practitioners and improve their professional ability and attainment, to make more contribution for the medical activities of our country and push the progress and development of the medical system of our country.

\section{Establish general practitioner major}

In order to train more general practitioners that meet the social development, we need to strengthen the training of general practitioner from colleges. Thus colleges should implement through following aspects: firstly, establish relevant majors, strengthen students' learning on relevant knowledge. At present, medical students in colleges have clear division of labor, with high profession, if they learn other knowledge based on the former knowledge, it will be beyond students' study ability and increase their learning burden, and the result also will not be obvious. Thus, colleges could 
combine the working features of general practitioners to establish new major or science, make its teaching points face to families or communities, to make general practitioners learn relevant knowledge and guarantee the learning effects; secondly, pay more attention to the research and projects on general practitioners. Medical industry can improve people's especially doctors' attention to general practitioner to promote the establishment of majors and strengthen colleges' training on general practitioners through increasing relevant content and researches; thirdly, increase general practitioner major into the teaching of graduates. Strengthen the analysis on the general practitioner professional theory through further research to change the present situation and promote the full play of general practitioners.

\section{Improve the teaching faculty of general practitioners}

In is essential to have a high level teaching faculty, if colleges want to train more general practitioners that meet social development. Thus colleges can do following things to provide guarantee for general practitioners in colleges: firstly, strengthen training of general practitioners backbones. Colleges can choose some teachers with strong ability and high teaching level from teachers in their own colleges to organize a teacher team, through training to complete them to provide excellent general practitioners; secondly, employ specialists as distinguished teachers, complete the teaching staffs, strengthen colleges' training for general practitioners to improve teaching quality; thirdly, strengthen the further study of teaching staffs. Colleges can select general practitioners from the nationwide through the way of mass-election, establish teaching staffs with high professions and strong teaching ability through further study to improve the teaching level of colleges to provide more excellent talents for the society ${ }^{[5]}$.

\section{Establish a wholesome general practitioner training system}

Colleges can provide regulate education for general practitioners and combine it with continuing learning, perfect the general practitioner training system, thus colleges can realize this target from following aspects: firstly, strengthen the exploration for general practitioner training system. Because there is no successful example for establishing perfect general practitioner training system, thus colleges should to perfect it from different forms and different explorations. Besides, colleges can combine it with further education to train general practitioners; secondly, orientation training. Colleges can provide measures of reducing tuition for remote areas through orientation training to provide ways for students with ideals, extent ways for the training of general practitioners, increase people's understanding for general practitioners to promote the establishment of the training mode; thirdly, strengthen students' practices. Theory is the premise of practice, practice is the way to check theories, thus in order to guarantee students' studying quality, check the training for general practitioners, practice is the best way. Thus colleges need to provide practice places for students, prepare for students for deepen theoretical knowledge and improve professional ability the communication with hospitals and communities. For students in the higher grade, colleges can set optional classes, combine theoretical knowledge with practical techniques, deepen understanding and grasp of professional knowledge, consolidate students' foundation, to lay foundation for students for their medical career.

\section{Establish perfect assessment system}

It is very important to strengthen the professional knowledge and technique of general practitioners to guarantee the ability of general practitioners. Thus, relevant departments can make requirements on the general practitioners from the following aspects: firstly, make industry qualification. Employment of general practitioners likes that of other industries, assess the employees to check whether it complies with the standard of medical industry, also be responsible for people's health; secondly, establish and perfect the registration assessment mechanism. In order to guarantee the professional knowledge and technique of general practitioners, our country also can learn experience form other developed countries, make assessment one for five years on the certificates of general practitioners, the ones cannot be qualified for two times, their certificates will be canceled. 
Thus form urge for them to guarantee their work ability; thirdly, make unified assessment mode. Relevant department should make unified assessment system for general practitioners to avoid phenomenon fraud and buying certificates that will reduce the whole level of this industry, influence the industrial regulation and leave hidden danger for people's health.

\section{Establish effective incentive mechanism}

Incentive mechanism has positive function to motivate human's working activity, stimulate the improvement of self ability. Thus strengthen the establishment of incentive mechanism is very important, relevant departments can do following things to promote the establishment of the training mode: firstly, strengthen the reform of medical industry of grassroots. Medical department in grassroots can attract more doctors to work in the remote areas and guarantee the improvement of our national medical level through reforms of human resource and social benefits; secondly, provide proper subsidy for general practitioners. Governments can increase number of doctors through provide subsidy for general practitioners, to improve their work activity through assessment on their working attitude and ability, to make more contribution for the society; thirdly, the country can promote the training on general practitioners through allowances. The government can provide proper some research projects and expenditures for general practitioners to strengthen the research on the work of general practitioners, to provide theoretical bases for general practitioners to improve their work quality and efficiency.

\section{Conclusion}

Above all, general practitioners mainly provide service for families or communities, thus it is necessary to establish a high level, high quality medical team. Thus, doctors should grasp the opportunity of medical reform to improve people's attention on general practitioners through establishing a perfect training mode for general practitioners, to play their functions to improve high quality medical service for residents, to solve the problems of medical difficulty and guarantee people's health. At the same time, perfect the medical health system, improve medical level to promote the progress and development of the medical service of our country.

\section{Acknowledgments}

Project name of this paper: Analysis on the Obstacles and Approaches for the Promotion of Grading Diagnosis and Treatment System of Xi'an City.

\section{References}

[1] Zhou Zhiheng, Zhen Chanjiao, Li Fangjian and so on. Problems of general practitioners training and the countermeasures in our country.Chinese medical innovation, 2014(36):111-113.

[2] Yang Hui, Xu Yanli. Trust me, I am a general practitioner--survey on the doctor-patient relationship in medical service from interpersonal trust.Chinese general medicare,2010,13(31):3477-3479,3484.

[3] Ge Caiying, Liu Wenjuan, Li Zhili and so on. Review of the on the job training for general practitioners of Fangzhuang community health service center during 2010-2013 and the enlightenment for future training.China Medical education technology,2014(5):576-579.

[4] Xu Jiao, Bo Hong, Dong Jingzhu and so on. Experience of Australian general practitioners and its enlightenment for China.Northwest Medical Education, 2014(3):427-429.

[5] Ye Linshu, Liu Zhe, Zhang Jie and so on. Research on the present situation of community general practitioners resource and discussion on its countermeasure. China Modern medicine,2011,18(32):122-124. 